\title{
If you have a hammer everything looks like a nail: 'traditional' versus participatory model building*
}

\author{
Authors: Klaus Hubacek ${ }^{1}$, Christina Prell ${ }^{2}$, Mark Reed ${ }^{1}$, Claire Quinn ${ }^{1}$, Nanlin Jin ${ }^{3}$, Joe Holden ${ }^{3}$, Tim \\ Burt $^{4}$, Mike Kirby ${ }^{3}$, Jan Sendzimir ${ }^{5}$ * \\ ${ }^{1}$ Sustainability Research Institute, School of Earth and Environment, University of Leeds, UK \\ ${ }^{2}$ Sociological Studies, University of Sheffield, UK \\ ${ }^{3}$ School of Geography, University of Leeds, UK \\ 4 Department of Geography, University of Durham, UK
}

5 International Institute for Applied Systems Analysis (IIASA), Laxenburg, Austria

* This work was carried out as part of project RES-224-25-0088, funded through the Rural Economy and Land Use Programme (RELU). RELU is funded jointly by the Economic and Social Research Council, the Biotechnology and Biological Sciences Research Council and the Natural Environment Research Council, with additional funding from the Department for Environment, Food and Rural Affairs and the Scottish Executive Environment and Rural Affairs Department. The research was conducted in close collaboration with staff from the Moors for the Future Partnership who are supported by the Heritage Lottery Fund (www.moorsforthefuture.org)

- A final version of this paper has been published in Interdisciplinary Science Reviews, Vol 32, Number 3, 2007.

- We would like to acknowledge the contribution of all the members of the project team: Aletta Bonn, Dan Chapman, Pippa Chapman, Gareth Clay, Stephen Cornell, Andy Dougill, Evan Fraser, Brian Irvine, Bill Kunin, Natalie Suckall, Sigrid Stagl, Lindsay Stringer, Mette Termansen, Sam Wong, Fred Worrall 
Abstract: The modelling of complex, dynamic and uncertain socio-environmental systems requires close collaboration between research disciplines and stakeholders at all levels. If models are representations of aspects of reality, how can we build models without inputs from people who interact with the system? This paper reflects on findings of case study research involving stakeholders in knowledge creation through conceptual and formal model building to support upland water catchment management. The uncertainty, multiple scales and conflicting understandings of stakeholders that are inherent in natural resource management necessitate a strong focus on participatory processes in integrated modelling. This leads to the recognition that problems and solutions should be identified by the stakeholders themselves, emphasizing the intersection and complementarity of lay and expert knowledge. Stakeholders in this context comprise varied groups such as land mangers (e.g. grouse moor managers and sheep farmers), water companies and water users, tourists, residents, policy-makers and researchers. Models are used at multiple stages to help formulate problems, create and compare conceptual understanding and explore implications. This requires that involvement of stakeholders should happen early in the problem formulation and research process to help answer the 'right' questions and provide 'relevant' outputs. This poses a number of interesting new challenges to the organisation of the research process. In contrast to traditional approaches of matching model components to expertise in the research team, modelling expertise must adapt to answer the questions and priorities that emerge from stakeholder engagement. 


\section{Introduction}

Increasingly sophisticated models are being used to represent highly complex environmental, economic and social systems. However, choosing which model to use often comes down to the experience, interests and expertise of the research team, rather than the characteristics of the problem or system to be modelled. Although the people who interact on a daily basis with this system may have very different views about what should be modelled and how, their views are rarely considered. The problem for the researcher with his or her pet model is that s/he wants to apply the model to the problem at hand rather than finding the appropriate model ${ }^{1}$.

Modelling has primarily been used by natural scientists as a means of capturing and predicting aspects of these systems, usually within disciplinary boundaries (e.g. hydrology, soil or atmospheric models). Economists also have a fairly long tradition of modelling components of socio-ecological systems, especially human-environment interactions (Ciriacy-Wantrup, 1952, Bergh and Straaten, 1997, Clark, 1976). Many of these economic models have been based on fairly stringent assumptions such as perfect information, optimal behaviour, and rational choice (Simon, 1955). More recently, sophisticated social models such as agent-based models (ABMs) have begun being used in environmental disciplines to describe and predict the way people (or 'social agents' or 'stakeholders') are likely to behave in response to different stimuli given various decision-rules (Gilbert and Troitzsch, 1999, Janssen, 2002). However, these models tend to treat the 'foreign systems' as given, exogenous or static (Matthews, 2006). In order to better approximate feedbacks and more accurately represent the complexity of real-life systems, there is an urgent need to integrate models from various disciplines with attention to the dynamic nature of these systems. In this way it may be possible to predict how people may respond to environmental change, and how their responses in turn are likely to influence their environment. Accurately representing human behaviour requires inputs from the people who live in and interact with the systems (e.g. landscapes) one is trying to model. This involves deriving "rules of behaviour" from the actual experiences, opinions and perceptions of stakeholders.

Researchers are increasingly taking inputs from stakeholders, collaborating with them to build and integrate models in what is known as participatory modelling (also referred to as 'mediated modelling', see van den Belt, 2004). This offers a number of advantages, as social agents are often intimately acquainted with a level of complexity and detail that is rarely represented in computational models. However, the appropriate inclusion of heterogeneous groups (e.g. with varying levels of formal education) that are typical of environmental stakeholders creates challenges for participatory modelling techniques. There is a need to develop methods to adequately select a representative range of stakeholders, codify and structure their various complementary or sometimes conflicting knowledges, and communicate model outputs in a form that is easy for them to understand and interact with.

In this paper, we review the role of modelling human-environment interactions and discuss how models can be effectively integrated, whilst being informed and guided by the inputs and feedback of relevant stakeholders. We illustrate this discussion with a case study where this is being done for a series of upland catchments in the UK. Since the project team is about half-way through this process we describe and reflect on our experiences in participatory model building through these first 2 years and relate them to discussions in the literature.

1 This problem is related to notions of a preanalytic vision (Schumpeter) or paradigm (Kuhn) where the researcher's perception predetermines which problems are perceived, how these problems are perceived, and approaches towards research more generally. (For a discussion see e.g. DALY, H. E. (1991) Towards an Environmental Macroeconomics Land Economics, 67, 255-259. or HODGSON, G. M. (1995) Economics and biology, Aldershot, Hants, England ; Brookfield, VT, E. Elgar Pub.) 


\section{The role of modelling in environmental studies}

The scientific tradition of generalisation is long established in environmental studies, but the approach has changed out of all recognition since the advent of high-speed computers. All models are selective and seek to simplify the complexity of the real world in different ways. Here the modeller continues to face a real dilemma: the continued success of 'traditional' models has shown that models need contain little or no relation to physical reality. In contrast, the (recent) development of 'theoretical' models, which possess some physical basis, allows the real possibility of application over a wide range of conditions and locations, as well as aiding our understanding of natural processes and systems (Anderson and Burt, 1985). Indeed, the development of physically based models has become so dominant in hydrology that in many cases the choice of model determines the problem to be solved, not vice versa. Dooge (1981) discussed issues relating to choosing and fitting a model to the problem; our approach requires a return to this earlier phase of hydrological modelling, whereby the very scope and range of the system to be modelled, let alone the choice of a particular model, is determined by the problem to be solved, which in turn is decided through consultation with the stakeholders and thus often outside the "formal model building'.

Once we know what the problem is, we can then select a class and type of model (see Figure 1). This is not meant to belittle the achievements of theoretical modelling studies over recent years; simply that the approach here takes a different starting point, in many ways a more risky approach, by delaying model selection until the problem has been defined. Put another way, it could be seen as reemphasising inductive science, that is generating ideas on the basis of observations, rather than deductive science, testing theoretical models (Burt, 2003). 
Fig. 1. A possible methodology for selecting a mathematical model

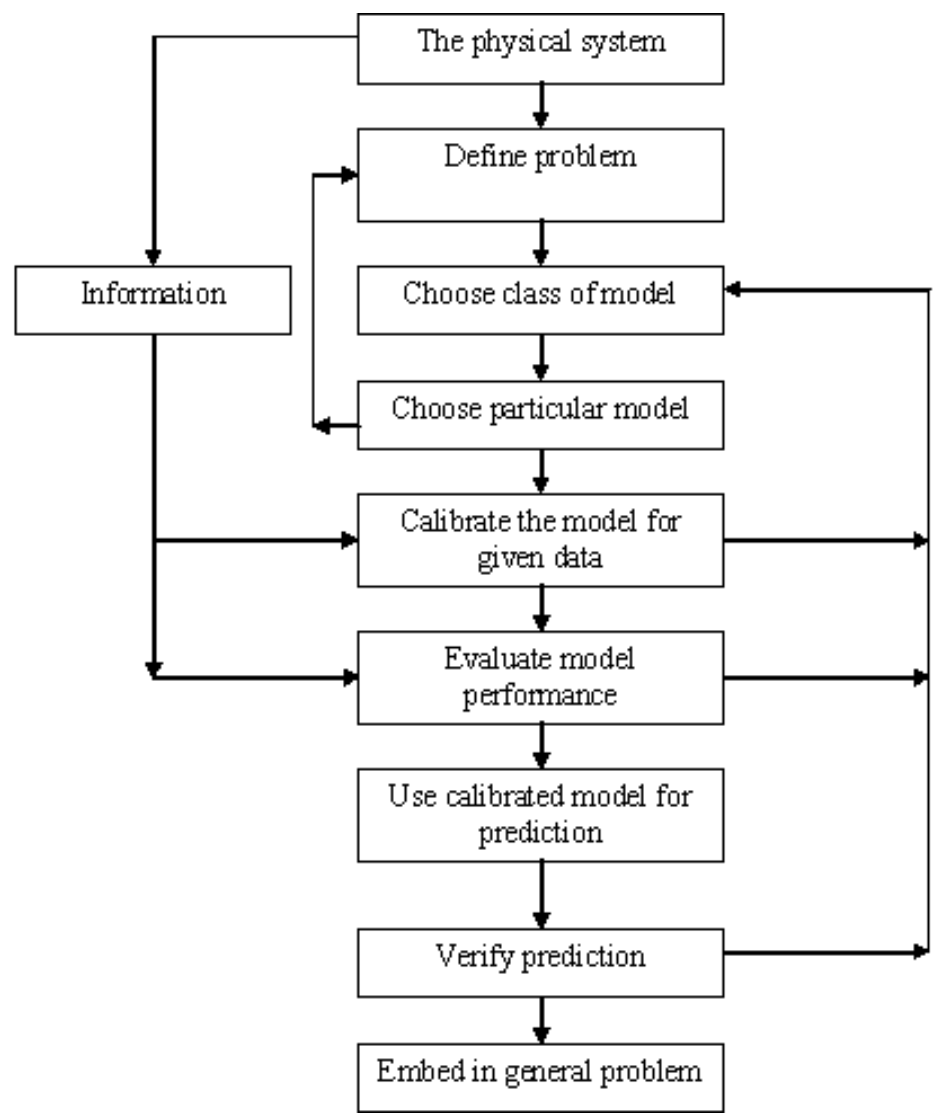

Source: After Dooge, 1981, and Anderson and Burt, 1985.

Thus from a modelling perspective, the argument for stakeholder-driven modelling would be that "the problem" and "the purpose" of the modelling work should take into account stakeholders' needs, perceptions of how the system works and what the problem is. The importance of participatory modeling, especially in water management, derives from the awareness of the inadequacy of traditional, engineering approaches to dealing with 'complex and ill-structured problems' (Giordano et al., 2007). It has become increasingly obvious that traditional problem solving and modelling approaches, based on optimization and 'factual knowledge', have to be combined with stakeholder-based policy design and implementation (Giordano et al., 2007, Funtowicz et al., 1998, Funtowicz and Ravetz, 1994, Funtowicz and Ravetz, 1990).

Participatory modelling does have a relatively long history. Since the 1960s a decision making process referred to as adaptive management has been evolving to address the twin challenges of learning and management in complex systems and has been applied to problems of human-ecology interactions (Holling, 1978, Walters, 1986, Gunderson and Holling, 1995, Gunderson and Holling, 2002, Walker et al., 2002, Sendzimir et al., 2007, Magnuszewski et al., 2005). Many processes similar to adaptive management have been developed in parallel over the past several decades including scenario planning (van der Heijden, 1996), participatory learning and action (Pretty et al., 1995), and soft systems methodology (Checkland, 1981, Checkland and Scholes, 1999) have been tested and applied in the emerging fields of Integrated Assessment (van de Kerkhof, 2001, Pahl-Wostl, 2002), Integrated Water Resources Management (Pahl-Wostl, 2007) and increasingly to facilitate group learning in businesses (Sterman, 2000, Sterman, 2002). 
A number of these adaptive management studies have focused on improving methods for working with stakeholders (Slocum et al., 1995) such as using modelling techniques for developing conceptual understanding of complex situations (Craig et al., 2002). One of the most promising avenues currently being pursued is to link modelling and stakeholder group exercises as parallel and interactive windows on stakeholder thought processes that are key to group decisions. Bousquet et al. (2002) and Dunajski et al. (2006) are two examples of this trend to integrate modelling (conceptual and/or formal) with role playing games. Stakeholders or representative actors are involved in these role playing games or simulation exercises to help model actors behaviour, test their potential responses or verify model components (Duke and Geurts, 2004).

Our own participatory modelling efforts have been guided by these attempts especially with regards to modelling stakeholders' behaviour in response to changes in their socio-economic or biophysical environment, then modelling manifestations or responses of their behaviour in the biophysical world through changes in chosen indicators, and finally the stakeholders' responses to the new environment they have influenced. All of these components in interaction with a strong bio-physical component are developed with inputs from stakeholders, thus building on these recent trends in the literature. We are engaged in an ongoing research project on the UK uplands that involves understanding and modelling the uncertainties surrounding current and future land management practices in six upland catchments in the Peak District National Park and other upland areas in the UK.

\section{Case study context}

The Dark Peak area of the Peak District National Park (PDNP) was chosen for its diversity of land use activities (for conservation, farming, tourism, water supply and game/fishing), and the range of social, economic, political and environmental pressures it faces. The PDNP was the first National Park to be established in England \& Wales, in 1951. With an estimated 22 million recreational visitor days annually, the PDNP is Britain's most visited National Park (National Parks Portal, 2004). It is situated at the southern end of the Pennine upland range, between three large cities. The Dark Peak is an upland area characterised by extensive moorland surrounded by enclosed farmland and intersected by deep narrow valleys. Soils are predominantly blanket peat (overlaying a Carboniferous Millstone Grit series), supporting predominantly dwarf shrub heath and blanket bog plant communities. Both habitats are internationally important, being recognised as key biodiversity habitats (UK Biodiversity Steering Group, 1995), containing a number of Sites of Special Scientific Interest (English Nature, 2003), and listed in the EU Habitats Directive as requiring special conservation measures. Britain contains 10-15\% of global blanket bogs and a similarly high proportion of dwarf shrub heath (Holden et al., 2007b, Tallis et al., 1998). They support nationally important breeding populations of moorland birds, including internationally important populations of several species listed in the European Commission Birds Directive as requiring special conservation measures (EN, no date). The PDNP contains a number of villages and towns and a population of 38,000 (2001 census). Reservoirs in the PDNP supply 450 million litres of water a day to the conurbations that surround it (Peak District National Park, 2001). PDNP residents are more reliant on agriculture, game birds, and tourism than the national average (2001 census). Most moorland is privately owned and managed for a combination of grouse and sheep production. Under the current Rural Development Regulation (EC Reg. 1257/99 and EC Directive 75/276) 93\% of the Park are designated as a Less Favoured Area. This designation for 'underdeveloped' rural areas entitles livestock farmers to subsidies that can help maintain economically viable farming on land that has low returns; the Park contains also Environmentally Sensitive Areas that provide payments to land managers to maintain landscape, wildlife or historical values.

The Peak District is, in some ways, typical of upland regions in Europe which tend to be economically marginal, environmentally sensitive and subject to many often conflicting types of land use (Holden et al., 2007b). Competing demands of conservation, water supply, recreation and tourism, agriculture and game management have led to a conflict of interests between many upland stakeholders. English Nature 
(English Nature, 2003) has classed a high proportion of Sites of Special Scientific Interest as being in unfavourable condition predominantly due to a combination of overgrazing and "inappropriate" burning. Such burning is carried out to create a mosaic of heather stands to maximise grouse populations (Holden et al., 2007a). These factors (compounded by historic atmospheric pollutant deposition) have also been blamed for increased erosion, with consequent effects on water quality (Tucker, 2003). Grazing levels have declined significantly (mainly as a result of Environmentally Sensitive Area agreements), but rotational burning continues to be practiced widely (Dougill et al., 2006).

A range of EU and international policy changes are influencing rural policy in UK uplands, with uncertain socio-economic and environmental implications. The most important with regards to the hydrology of the region is the EU's Water Framework Directive, which requires all inland and coastal waters to be in "good status" by 2015. The biggest challenge for UK compliance will be the process of catchment management itself, but more specifically, the reduction of diffuse pollution linked to land management (Mitchell, 2005). Another problem, specifically of importance to water companies is water colouration as potable water is subject to legal water colour limits. The water colour problem has increased in UK uplands over the past few decades and there appear to be multiple drivers of this change (Worrall and Burt, 2005). Such drivers may include proximate local factors such as moorland drainage (Holden, 2005), regional factors such as changes to atmospheric deposition chemistry (Evans et al., 2006) and underlying factors such as increase in traffic or change in land management due to changes in funding regimes.

\section{Finding the nail: stakeholder involvement in model development}

Existing mono-disciplinary models are a poor starting point for understanding and predicting change in complex and dynamic systems such as UK uplands. Top-down, expert-led modelling approaches risk producing outputs that have little relevance to the kinds of issues being experienced by stakeholders on the ground. By taking a more bottom-up approach to model development that involves stakeholders from the outset, it may be possible to identify and prioritise the problems that need to be solved first, and use this to determine the scope and choice of models to apply. Thus, sticking with our metaphor, we need to find the nail, and determine whether in fact it is a nail, before we even start thinking about hammers.

\subsection{Identifying Stakeholders and Issues}

Stakeholder involvement in model development needs to be founded on a rigorous and sensitive approach to stakeholder identification and selection. Many resource management exercises refer casually to stakeholders as if their existence and identity were self-evident. In practice, stakeholders are both selfidentified and construed as such by others. Different stakeholders may have widely divergent perceptions about who holds a valid stake in the focal issue, and these perceptions may be influenced by existing conflicts and hidden agendas. Some stakeholders are associated with formal organisational roles and interests, others are not. In addition to these challenges, there is a dialectic between problem definition and stakeholder identification. If the issues are defined without consulting stakeholders, then the issues may not be relevant to their needs and priorities; and yet, the issue must be defined before it is possible to identify those who hold a stake in it. To complicate matters further, many stakeholders might not be interested in participating due to time constraints, or lack of interest or understanding about how the issues under discussion relate to their daily lives (for a discussion of such problems see e.g. Renn et al., 1995, Smith, 2003). The issue then becomes of which stakeholders to include in such a process (Hubacek, 2006, Prell et al., 2007b).

In response to these challenges, stakeholder analysis has gained increasing attention and is now integral to many participatory natural resource management initiatives (Mushove and Vogel, 2005). However, there are a number of important limitations to current methods for stakeholder analysis. For example, 
stakeholders are usually identified and categorized through a subjective assessment of their relative power, influence and legitimacy (Mitchell et al., 1997, Frooman, 1999). Stakeholder selection methods have often overlooked the role communication networks can play in categorising and understanding stakeholder relationships. We tackled these problems through an iterative process of stakeholder analysis in focus groups, combined with semi-structured interviews, follow-up phone interviews with original focus group participants and social network analysis.

We started by conducting a focus group with members of a stakeholder organization we previously knew, and two key stakeholder organizations that they had identified. To avoid bias arising from initial group composition, focus group data were triangulated through semi-structured interviews with eight stakeholders identified during the focus group to represent different land management perspectives. The aim of the focus group and subsequent interviews was to evaluate and adapt the proposed aims of the project in order to ensure it was focusing on relevant issues and identify and categorize stakeholders. These led to the suggestion that the project should focus more strongly on a single issue in order to achieve its aims within the time available. There was near unanimous agreement that heather burning was the most pressing land management issue due to the Government's ongoing and highly contentious review of the Heather and Grass Burning Code (Dougill et al., 2006, Hubacek, 2006).

The focus group and interviews also identified over 200 relevant stakeholder organizations, so it was necessary to develop some sort of selection or sampling strategy. Given the need for small sample sizes for in-depth qualitative interviews and focus groups, achieving fair representation can be a major challenge. If sampling is deemed to be unrepresentative, then the legitimacy of research outputs may be undermined. However, by developing distinct categories, stakeholder analysis was used to stratify the sample, so that random or snowball sampling was used within each stakeholder category, ensuring all the major groups were represented. To do this, stakeholders were initially categorized during the focus group, and information was elicited about the most effective way to gain the support and involvement of these stakeholders. Successive interviews resulted in the addition and sub-division of stakeholder categories. The eight stakeholder group categories that emerged from this process were water companies; recreational groups; agriculture; conservationists; grouse moor interests (consisting of owners/managers and game keepers); tourism-related enterprises; foresters; and statutory bodies. These categories were then used to guide our 'snowball' sample: one or two individuals from each stakeholder category were interviewed; these led to further interviews until both names and land management issues began to repeat. A total of 22 interviews representing all categories were thus conducted. These interviews were used to deepen our knowledge of the current needs and aspirations of those who work, live and play in the Park (Dougill et al., 2006, Prell et al., 2007b).

In some 80 further interviews, stakeholders were asked about their relationship with other stakeholders in the park. These interviews were the basis for a social network analysis (SNA) which revealed the various roles individuals played and identified the more peripheral stakeholders (Prell, 2003, Prell et al., 2007a, Prell et al., 2007b). These groups were then targeted for inclusion into the research process to reduce bias, strengthen the legitimacy of the sample group, and to include a variety of relevant knowledges to the research process.

In addition to this, SNA provided the option of selecting individuals who are either different or similar to each other. Similar individuals are typically better able to communicate tacit, complex information, as there tends to be higher mutual understanding between them (Mark, 2003, Ruef et al., 2004a, Skvoretz et al., 2004, Friedkin, 1998, Ruef et al., 2004b, Cross and Parker, 2004). On the other hand, in order to elicit a wider range of views, it may be appropriate to select individuals who are very different to each other (Newman and Dale, 2007, Crona and Bodin, 2006). In our research, stakeholders wanted focus groups to be composed of individuals who did not know each other well in order to enhance learning between participants, and it was possible to do this using outputs from the SNA (Prell et al., 2007a). 


\subsection{Developing and Refining a Cognitive Map of the System}

Once stakeholders have been selected for involvement in model development, the next step is to capture, codify, integrate and represent stakeholder perceptions of system structure and function, and integrate this with the knowledge of researchers as expressed in peer-reviewed literature. To do this, semi-structured interview transcripts were analysed using a grounded theory approach that uses key words to code text in order to generate cognitive maps or flow charts (Glaser and Strauss, 1967, Corbin and Strauss, 1990). These findings were combined with information from a literature review (Holden et al., 2007b) to develop a cognitive map from which future scenarios and likely outcomes for the study area were derived. A working group of ten researchers further refined this cognitive map in workshops, using the initial phases of the system dynamics approach to allow for group learning ((Dougill et al., 2006, Prell et al., 2007b). This is in line with similar approaches linking more formal modelling and stakeholder group exercises (see section 2). Figure 2 shows part of the cognitive map that was developed, focussing on drivers affecting concentrations of dissolved organic carbon (DOC) from upland catchments, referred to as 'water colour' in the figure. As this cognitive map is extremely complex, researchers identified key scenarios within the map and presented them as storylines to stakeholders at a multi-stakeholder focus group. These were used to stimulate a discussion designed to refine the cognitive map further (Dougill et al., 2006).

Although the influence of drivers such as climate change, grazing and burning on DOC are discussed at length in the literature (Holden et al., 2007a, Holden et al., 2007b, Worrall and Burt, 2005), there is currently little or no acknowledgement of links to drivers such as cultural and demographic change, recreational pressure, agricultural markets or Common Agricultural Policy reform. By incorporating stakeholder perceptions of the interactive effects of drivers, Figure 2 provides a more complex, holistic and interdisciplinary representation of factors influencing DOC levels in UK uplands. For example, it considers the changing role of forestry, the factors leading to scrub development, and suggests a variety of factors that may influence levels of managed and accidental fires and grazing. These factors of course interact so that a decrease in cooler managed burns may lead to increased of wildfire as the heather cover becomes more woody and shrub-like and will burn at much hotter temperatures in uncontrolled conditions. Both managed burning and accidental fires have been linked to elevated DOC levels (Holden et al., 2007b), but there are a variety of factors that may either increase or decrease the area of managed and accidental fires, including: changes in burning regulations; increased adoption of managed burning strategies; cultural change leading to a ban on hunting wild birds; and, a reluctance to close moorland at risk from accidental fire due to increased recreational pressure despite a tendency to drier summers. 
Fig. 2. Cognitive map

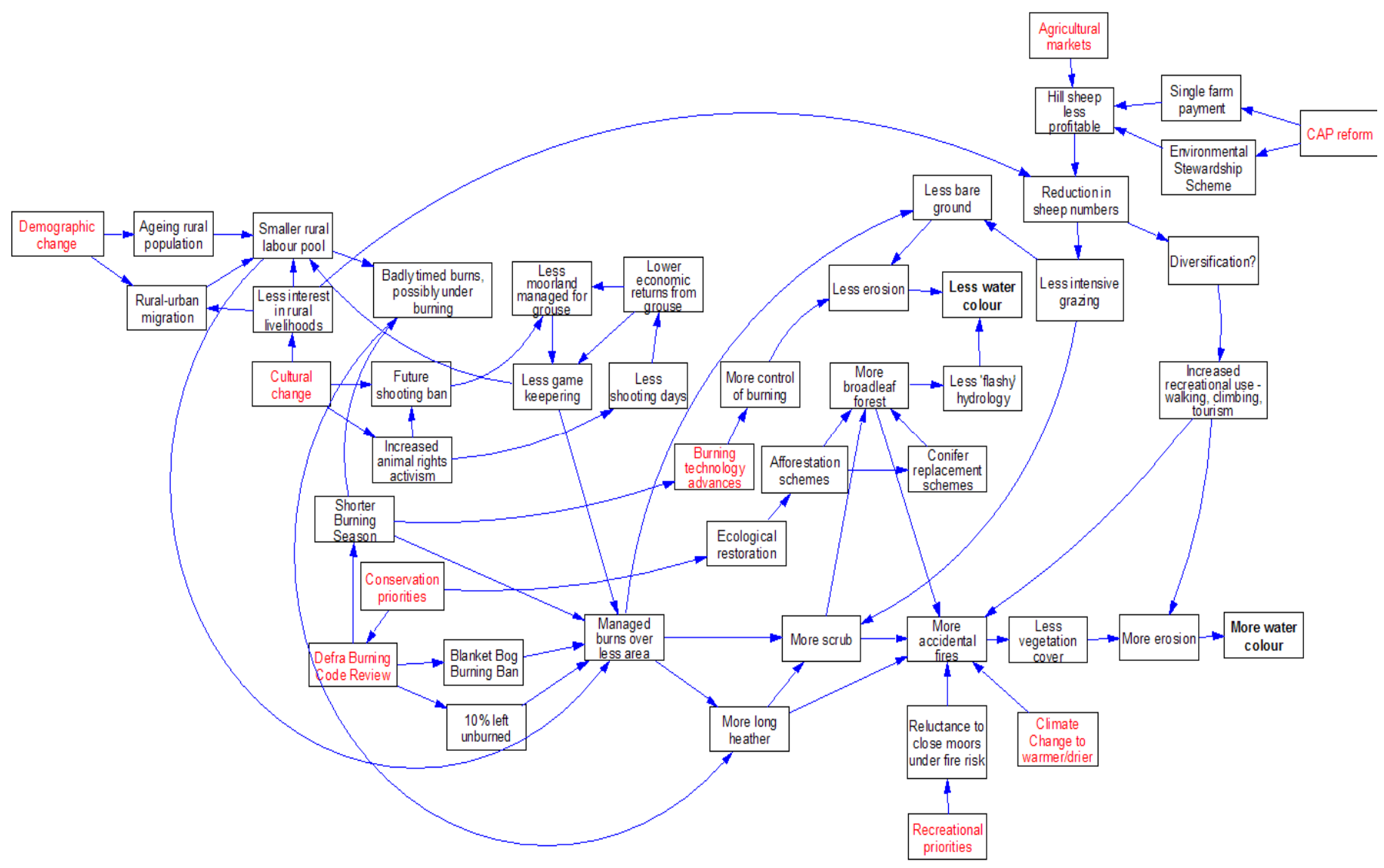

The conceptual map in Figure 2 helped visualize the important relationships amongst variables spanning a range of disciplines that are not usually connected due to disciplinary boundaries or disciplinary blind spots, and the scientists' own conceptual map of how the system works. This map helped to identify which connections are not well researched or understood - such as whether heather burning influences water colour and DOC - because of a lack of field data. Other processes are easier to model as data are more readily available, such as how grazing densities impact vegetation cover and erosion. Thus the conceptual map helps to prioritize further research steps. One of the challenges in this case was to ensure both that stakeholder concepts were taken account of, and that scientific concepts were adequately merged into the cognitive map.

The conceptual map, derived from stakeholder interviews and inputs from 'experts', represented a wide variety of stakeholder knowledge and perceptions. As such, no single stakeholder or sub-set of respondents could legitimately check how the knowledge of the whole group had been represented in the model. However, by using Grounded Theory Analysis to analyze interview transcripts, it was possible for the cognitive map to emerge from the drivers of change and relationships between system components discussed by stakeholders (Dougill et al., 2006). This integration of knowledges from stakeholders and researchers is a form of cross-validation. In general, these knowledge sources corroborated each other, providing more depth and detail than either approach could have provided alone. A number of discrepancies between these knowledge sources were discussed during a focus group with stakeholders.

The resulting model became highly complex, and as such was very difficult to communicate effectively to stakeholders; Figure 2 is just one segment of the overall cognitive map (Dougill et al., 2006). Thus we ran into a number of communication problems during this meeting as the models were deemed to 
simplistic by some of the stakeholders whereas other had difficulty to communicate on this rather abstract level. We found that existing techniques used in participatory modeling are of little help in accessing knowledge held by groups with little formal education, and who may not be as 'literate', vocal or outspoken (Kolb, 1984). In addition to this, the use of powerpoint projection, interacting with software and the usual paraphernalia associated with focus groups might have intimidated some stakeholders to whom all this is alien.

One response to these problems may be to illustrate more complex story-lines or scenarios with a Geographical Information System (Sharma et al., 2006) and photographs that have been digitally manipulated (Tress and Tress, 2003) to show landscapes before and after each scenario. However, this approach, like many visualization techniques, poses the risk of visual bias. Issues that can easily be represented visually (e.g. land cover change) may receive more attention from focus group participants than less easily visualized aspects (such as cultural or demographic change). Alternatively, such exercises may simply capture visual preferences as participants often just respond to the landscape they prefer rather than the issues being discussed (Pedersen and Persson Waye, 2004). To address this concern, we are currently investigating the use of short films, moving away from the exclusive use of landscapes, and using visual metaphors to communicate issues that are hard to visualize in any other way.

\subsection{The right hammer for the job? From cognitive map to integrated computational model}

Once the relevant issues and stakeholders have been identified, and their knowledge has been codified and integrated with research insights in the cognitive map, it is possible to commence turning this essentially qualitative information into a quantitative computational model (step three below). This participatory approach should develop models that can help address issues pertinent to stakeholders, and provide outputs that will justify their investment in the process. By effectively communicating model outputs, as discussed above, it may even be possible for stakeholders to help interpret model outputs and refine model development in collaboration with researchers. Such feedback may provide a rapid and highly constructive form of model validation (Stringer and Reed, 2006).

Development of an integrated computational model that captures the essence of the cognitive map is still underway in this project. It has required modellers from very different disciplinary backgrounds to learn how to work together, and work out how their models can be meaningfully integrated. Hence, the following sections remain primarily descriptive and conceptual in nature, but reflect a long process of academic debate and engagement.

\section{Developing an Integrated Computational Model}

To develop an integrated model, we plan to host a series of focus groups and follow-up interviews to develop a series of management options that are then to be formally modelled using the cognitive map as the basis for understanding how various forces interact. Moving the cognitive map to a working dynamic model of upland regions involves extensive hydrological and ecological research, as well as socioeconomic modelling. Although a complex task, once complete, we hope to be able to test the likely outcome of various policy decisions or management plans. Results of the model will then be presented back to the stakeholders in a further series of focus groups to allow them an opportunity to modify management plans and strategies in light of the model outputs. The rest of this section describes the various model components and discuss possible ways of integrating these models.

The conceptual maps developed in collaboration with the stakeholders have served as a framework for the development of the integrated model. For this we have to step back from the complexity of the cognitive map and identify the subsystems, drivers and potential models that can be used to link human behaviour to biophysical effects, which in turn influence land managers in their decisions (Figure 3). 
Fig. 3. Integrated model components

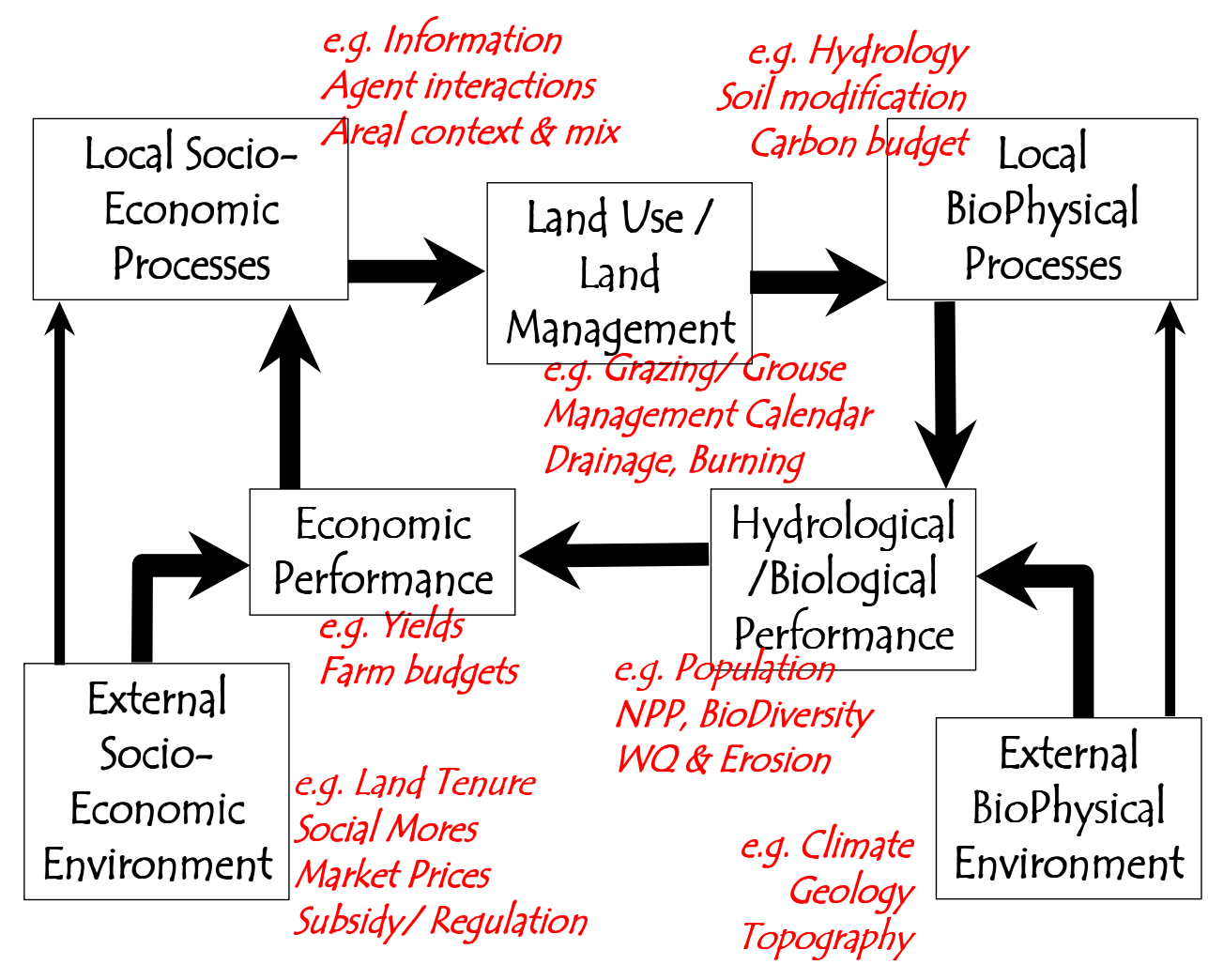

The integrated model has three major sub-models: the agent-based model (ABM), the soils and hydrological and carbon model (PESERA) and the biodiversity model. The ABM mainly deals with farmers' decision making processes given data on (1) economic conditions (for example, price of sheep, subsidies, and the income from providing grouse for shooting); (2) natural conditions; and (3) institutional constraints. The biophysical model (PESERA) provides data for the natural constraints but also for the biophysical responses to the farmers' land management choices. The inputs of PESERA are from the farming strategies generated by the ABM and the outcomes of the biodiversity model. The biodiversity model examines the dynamics of sheep and grouse populations, which will be fed back into the ABM based on some notion of calculated accrued income and some measure of changes in biomass, erosion and other indicators deemed to be important for the land manager's decision making (Jin et al., 2007).

\section{Modelling human behaviour - Agent-based modelling}

There is a paucity of social science data for the construction of decision rules for ABM (Parker et al., 2003). While the use of integrated modelling for investigating human-environmental systems is growing, there is some recognition of underlying data problems for both biophysical as well as social science models with a special focus on the latter (Matthews, 2006). Of special interest for us is the problem of how to model the behaviour of the land managers (the agents) in integrated socio-ecological systems. Some studies have used household survey data to parameterise their agents and to form the basis for decision rules (Manson, 2005, An et al., 2005).

This study uses the first level of participation in ABM identified by Parker et al. (2003) where stakeholders are involved in all stages of research: from model development through to model validation. The scenarios developed from the cognitive map form the basis of a detailed questionnaire developed to elicit the decision-rules for the ABM. Respondents who are land owners, agents for large land owners, 
tenant farmers and grouse moor managers have been contacted to take part in the questionnaire for the ABM. Each scenario is presented to the respondents and they are asked how they would change their management strategies in relation to grouse and/or sheep farming under each scenario. They are also asked to rate how confident they are that the changes in management they identify truly reflect the choices they would make under those scenarios. These so-called choice experiments had originally been developed in environmental economics as an extension or variant of contingent valuation. The choice experiment employs a series of questions with several alternatives that are designed to elicit responses that allow the estimation of preferences over attributes of an environmental state (Adamowicz et al., 1998).

There is a trade-off between capturing all the data we would like and constructing choice-experiments that can run in the time available. This requires careful prioritization and selection of scenarios to be addressed in the choice experiments. In order to reduce the potential for this to introduce bias, the scenarios were based on the cognitive map, which in turn was derived from interviews with stakeholders. As a consequence, the results of the choice experiments should in theory reflect stakeholder priorities rather than researcher's biases.

\section{Modelling biophysical systems - soils, hydrology and ecosystems}

At the core of the biophysical model is an existing hydrological model (PESERA) which will be adapted to better fit its project-specific purpose, i.e. hopefully the stakeholders' needs. This model is being used to predict runoff and erosion across Europe and has been developed and improved over the last 15 years (Kirkby \& Neale 1987, de Ploey et al. 1991, Kirkby and Cox 1995, Schofield and Kirkby 2003). It provides a core bio-physical platform into which additional elements can be built to tailor it to project needs. PESERA has an explicit basis in physical hydrology, with validation across Europe at a $1 \mathrm{~km}$ grid resolution for sediment yields. It can, however, be adapted to application at a variety of scales. For the purposes of this project we will parameterise it for $50 \mathrm{~m}$ resolution. The use of PESERA as the model platform enables us to ensure that information is available in a spatially-explicit way with topography, soil types, rainfall data and other relevant factors incorporated. This should enable us to show how one activity in one part of the catchment will have a different impact/risk associated than the same management in another part of the catchment. This will allow the development of distributed decisionmaking in a move away from simple blanket policies.

PESERA will be extended to predict the transport of solutes through the catchment as well as the transport of solid material. Specifically the model will estimate non-point-source losses of nitrogen, phosphorus and carbon, both in solution and adsorbed to sediment. The combined model will provide information on rates of runoff and water quality, linked to explicit vegetation growth and/or crop models. It provides an explicit link between future land use and possible changes in eutrophication and sedimentation in reservoirs, degradation of peat moorland, and changes in water production.

Due to the importance of uplands as Britain's largest carbon store (Cannell et al., 1993, Milne and Brown, 1997), and it being frequently referred to in stakeholder meetings, another new extension of the PESERA model is a carbon budget model (Worrall et al., 2003). The resulting model should allow us to assess important management options including grazing intensity and heather burning.

To reflect the uplands' importance for biodiversity and the strong dominance of conservation stakeholders, the final model is also extended to include a biodiversity component. Much of the biodiversity interest in uplands rests in the conservation of healthy, diverse biotic communities across broad ranges of species that are not individually of high conservation priority. To assess these biodiversity values, we are developing models in which the area and connectivity of land cover categories are used to project overall future diversity patterns of sets of habitat-restricted species. In order to do this we need to translate land managers behavior into changes in land use, which is interacting with abiotic conditions (such as altitude, slope, aspect, soils, hydrology), and is then translated into land cover changes over time. This aspect of the model allows modeling the impacts of land cover change on biotic communities and species of conservation interest. 
The agent-based model will provide data on human responses to socio-economic and political drivers, and that this will provide inputs to the physical model. At the same time, physical environmental change will influence decision-making and the physical models will therefore provide inputs to the agent-based model. Hence the modelling becomes truly integrated.

\section{Challenges of model integration and participation}

\subsection{Reflection on Model integration}

Initially the main models are built separately and tested against real data and by checking whether the outputs of the model fit expert knowledge. Once all three models are tested and validated, we integrate them into a single modelling framework. The sub-models exchange information within the framework of the integrated system.

Each of the models has its own inherent model logic with specific assumptions and type and format of data it can process. For example, PESERA has been designed to provide hydrological and erosion data on a 50m grid cell but farmers think in terms of their fields, topographical features, soil types experienced through different growth rates of plants and height of heather rather than kilograms of biomass, the measurement unit PESERA 'understands'.

With regards to space, the system boundaries are legal boundaries in the case of the behavior of the farmer; but are less stringent and less clearly defined in the case of the various biophysical models which allow for inflows and outflows from and to the respective sub and supra-systems. Therefore, we have to account for emerging properties in both the biophysical models and the ABM. For example, a field with various vegetation features will have different impacts on biodiversity or water quality dependent on the location and proximity of these features to each other. This can then lead to a multitude of behavioral responses of the farmer dependent on subjective perception of these features.

Another important category is time. Farmers usually change land use at a yearly time scale, orienting their decision on seasonal stages, whereas PESERA runs on daily basis. How to reset data from ABM to fit PESERA was a concern. ABM creates the farming strategies to describe land use by seasons. In order to exchange data between ABM and PESERA, an ABM farming strategy has to be translated into daily activities (even if constant) for PESERA. Another aspect of time is that farmers might change their responses over time due to new information, learning from others and influences from their social system. This is something that is very difficult to elicit from questionnaires as the get increasingly complex and increasingly test the patience of the respondents.

These different qualities and measurements need to be translated between the different models and the questionnaires trying to illicit categories and responses from farmers. For the modeler it is important to recognize that the land managers make decisions according to soil types and slopes and rougher approximations rather than precise, crisp numbers and categories. In order to deal with these differences in language we conducted qualitative interviews with farmers and experts to elicit meaningful categories (i.e. decisions rules farmers might use, parameters they might observe) some of which could be in qualitative terms. From the model side we looked at the parameters and inputs the model could understand and tried to match them iteratively with the more qualitative decision parameters of the agents - i.e. through pilot questionnaires and meetings between the modelers and farming experts. Some elements got lost in translation - and we might not even know which at this point. Thus we plan to evaluate these categories with the farmers.

\subsection{Challenges for participation}

Especially for biophysical modellers used to describing and modelling the environmental system through deductive science, the participatory approach has been both refreshing and frustrating. Partly, this was 
because the biophysical modelling could not progress until the issues emerged from the participatory process. For example, there are hundreds of potential water quality parameters that could be modelled, each of which would require different datasets to be modelled effectively. For natural scientists to begin a project without knowing what would be modelled was an unfamiliar experience.

Despite this focus on formal model building it is important to point out the importance of non-formal more qualitative approaches and aspects of the participatory research process such as trust, appreciation and empowerment. The involved participants/stakeholders are not just input to 'our research' but also have lives and commitments outside the research project. This is an important constraint to realize as participants often invest heavily in terms of their time commitment and expect certain outcomes from the project. Thus the number and length of questionnaires pose an important restriction to the modelling process as outlined in this paper when trying to avoid participants' fatigue.

Despite stakeholders participation in model building the model to some extent always remains a black box as the nooks and crannies, assumptions and shortcomings are only known to the modeller. Land managers who have developed a good understanding of their actions and consequences in daily land management are asked to believe that the model represents their 'stylized actions' - which requires a considerable amount of trust on the part of stakeholders.

The outcomes of the process/models might not be the ones the participants had anticipated or hoped for. There is often a strategic element in why different stakeholders would want to engage such as to gain access to policy processes or having a careful eye on what is going on in addition to a genuine interest to learning and gaining insights into the working of their surrounding. Thus recognition of the underlying power dynamics and potential pitfalls are a precondition for a successful process.

Such a process might take a long time especially if one works with stakeholders. A related problem is a potential mismatch of the time necessary to build the models and the policy process one plans to inform (or simply beyond the patience of people involved). Stakeholder participation is likely to lead to new and very different types of questions and thus might aggravate the time issue (van Daalen and Bots, 2007). We have started the process with initial interviews about 2 years ago and stakeholder need quite some patients to keep committing time to an output they might not agree with, not entirely understand and that might not change anything anyway. Stakeholder buy-in is not only required from people on the ground but also those that can influence change. People are not interested in participating in yet another 'talk shop' if there is not a worthwhile outcome in the end. Thus there might be a mismatch of what the process needs to be in order to be most beneficial for the stakeholders and what the researchers would like to get out of the project.

But the process itself and the associated learning has been identified as a goal worth pursuing. Stakeholders learn about each other and about their social and physical environment simply by participating in these processes - so goes the theory. This would require some level of continuity of participation which is difficult to achieve. Often larger organizations are represented through different individuals with little knowledge of what has happened before or just very different personalities or opinions than their predecessor or other parts of the same organization.

This variety of personality and people which is clearly the most important strength of participatory modelling is also its largest weakness. Participants' capacity to process information might be different from each other which requires a representation of outputs that are easy to understand by non-experts and as not to exclude anybody early on. People also respond very differently to the outputs of the model. Outputs are usually numbers which need to be translated in indicators of relevance to the stakeholders usually again expressed in numbers. But people respond differently to different information. Aesthetic values and other more qualitative information is lost or needs to be explicitly added through various complementary tools in which the modelling process is embedded and the ways in which outputs are communicated. The formal part of the exercise addresses the cognitive processes rather than emotive sides of decision making but emotions play a very important role especially when conflicts are involved.

Despite these calls for caution with regards to enthusiasm in participatory model building this is enthusiasm is well founded. Arguments in favour are its ability to enhance the relevance and legitimacy of the models for decision-making, this aspect refers especially to normative motives (e.g. democratic 
ideals and people's right to participate in environmental decision-making; Barber, 1984; Elster, 1998). Pragmatic arguments for public participation in model development are enhancing the quality of decisions that are made, by incorporating local knowledge with other knowledge sources (Webler et al., 1995; OECD, 2001). There are also a series of arguments around the efficiency of participatory decision-making processes with regards to the availability of better information but also in terms of attainable durable solutions more likely to be accepted by stakeholders (Forester, 1999, Smith, 2003). In other words, decisions informed by outputs of models that have been developed through collaboration with representative stakeholders are less likely to be contested than those based on the outputs of "black box" models. Another strong support of bottom-up model building has come from the recognition of the uncertainty, multiple scales and conflicting understandings of stakeholders that are inherent in natural resource management. This has lead to a recognition that problems and solutions should be identified by the stakeholders themselves, emphasizing the intersection and complementarity of lay and expert knowledge. Thus the involvement of stakeholders should happen early in the problem formulation and research process to help answer the 'right' questions and provide 'relevant' outputs based on the appropriate tools or models. This poses a number of interesting new challenges to the organisation of the research process leading to higher levels of uncertainties for the researchers and the funding agencies. A considerable amount of trust is required from the funding agency to devote money to financing a process with not clearly defined outcomes and flexibility to allow for modifications of design and ultimately the composition of the project team to provide the expertise the problem requires. 


\section{References:}

ADAMOWICZ, W., BOXALL, P., WILLIAMS, M. \& LOUVIERE, J. (1998) Stated Preference Approaches for Measuring Passive Use Values: Choice Experiments and Contingent Valuation American Journal of Agricultural Economics, 80, 64-75.

AN, L., LINDERMAN, M., QI, J., SHORTRIDGE, A. \& LIU, J. (2005) Exploring complexity in a human-environment system: An agent-based spatial model for multidisciplinary and multi-scale integration. Annals of the association of American geographers, 95 54-79.

ANDERSON, M. G. \& BURT, T. P. (1985) Modelling strategies. IN ANDERSON, M. G. \& BURT, T. P. (Eds.) Hydrological Forecasting. Chichester, Wiley.

BERGH, J. C. J. M. V. D. \& STRAATEN, J. V. D. (1997) Economy and ecosystems in change : analytical and historical approaches, Cheltenham, UK ; Lyme, NH, Edward Elgar.

BOUSQUET, F., BARRETEAU, O., D'AQUINO, P., ETIENNE, M., BOISSAU, S., AUBERT, S., LE PAGE, C., BABIN, D. \& CASTELLA, J. (2002) Multi-agent systems and role games: an approach for ecosystem co-management. IN JANSSEN, M. A. (Ed.) Complexity and ecosystem management: the theory and practice of multi-agent systems. Cheltenham, UK, Edward Elgar Publishers.

BURT, T. P. (2003) Realms of gold, wild surmise and wondering about physical geography. IN TRUDGILL, S. \& ROY, A. (Eds.) Contemporary Meanings in Physical Geography. London, Arnold.

CANNELL, M., DEWAR, R. \& PYATT, D. (1993) Conifer plantations on drained peatlands in Britain: a net gain or loss of carbon? Forestry, 66, 353-369.

CHECKLAND, P. (1981) Systems thinking, systems practice, New York, USA, John Wiley.

CHECKLAND, P. \& SCHOLES, J. (1999) Soft systems methodology in action, New York, USA, John Wiley.

CIRIACY-WANTRUP, S. V. (1952) Resource Conservation: Economics and Policies, Berkeley, Ca., University of California Press.

CLARK, C. W. (1976) Mathematical bioeconomics: the optimal management of renewable resources, New York, Wiley-Interscience.

CORBIN, J. \& STRAUSS, A. L. (1990) Grounded Theory Research - Procedures, Canons and Evaluative Criteria. Qualitative Sociology, 13, 3-21.

CRAIG, W., HARRIS, T. \& WEINER, D. (Eds.) (2002) Community participation and geographic information systems, London, Taylor and Francis.

CRONA, B. \& BODIN, O. (2006) What you know is who you know? Communication patterns among resource users as a prerequisite for comanagement. Ecology and society, 11, http://www.ecologyandsociety.org/vol11/iss2/art7.

CROSS, R. L. \& PARKER, A. (2004) The hidden power of social networks : understanding how work really gets done in organizations, Boston, Mass., Harvard Business School Press.

DALY, H. E. (1991) Towards an Environmental Macroeconomics Land Economics, 67, 255-259.

DOOGE, J. C. I. (1981) General report on model structure and classification. IN ASKEW, A. J., GRECO, F. \& KINDLER, J. (Eds.) Logistics and benefits of using mathematical models of hydrologic and water resource systems. IIASA Proceedings Series Volume 13. Laxenburg, Austria, International Institute for Applied Systems Analysis (IIASA).

DOUGILl, A., REED, M., FRASER, E., HUBACEK, K., PRELL, C., STAGL, S., STRINGER, L. \& HOLDEN, J. (2006) Learning from doing participatory rural research: Lessons from the Peak District National Park Journal of Agricultural Economics, 57, 259-275.

DUKE, R. D. \& GEURTS, J. L. A. (2004) Policy Games for Strategic Management Pathways into the Unknown, Purdue University Press. 
DUNAJSKI, A., KROLIKOWSKA, K., KRONENBERG, J., MAGNUSZEWSKI, P., MALISZEWSKA, K., SENDZIMIR, J. \& SLODKA, A. (2006) Role-Playing Simulation as an educational tool for sustainable development - Karkonosze Mountains case study. Simulation and Gaming, Under Review.

ENGLISH NATURE (2003) England's best wildlife and geological sites; the condition of SSSIs in England in 2003, Peterborough, English Nature.

EVANS, C., CHAPMAN, P., CLARK, J., MONTIETH, D. \& CRESSER, M. (2006) Alternative explanations for rising dissolved organic carbon export from organic soils. Global Change Biology, 12, 2044-2053.

FORESTER, J. (1999) The deliberative practitioner, Cambridge, MA, MIT Press.

FRIEDKIN, N. E. (1998) A structural theory of social influence, Cambridge ; New York, Cambridge University Press.

FROOMAN, J. (1999) Stakeholder influence strategies. Academy of Management Review of Economics and Statistics, 24, 191-205.

FUNTOWICZ, S. \& RAVETZ, J. (1994) The Worth of a Songbird: Ecological Economics as a Postnormal Science. Ecological Economics, 10, 197-207.

FUNTOWICZ, S., RAVETZ, J. \& O'CONNOR, M. (1998) Challenges in the Use of Science for Sustainable Development. International Journal of Sustainable Development, 1, 99-107.

FUNTOWICZ, S. O. \& RAVETZ, J. (1990) Uncertainty and Quality in Science for Policy, Dordrecht, Kluwer.

GILBERT, N. \& TROITZSCH, K. G. (1999) Simulation for the social scientist, Milton Keynes, Open University Press.

GIORDANO, R., PASSARELlA, G., URICCHIO, V. F. \& VURRO, M. (2007) Integrating conflict analysis and consensus reaching in a decision support system for water resource management. Journal of Environmental Management, 84, 213-228.

GLASER, B. G. \& STRAUSS, A. L. (1967) The discovery of grounded theory : strategies for qualitative research, Chicago, Aldine Pub. Co.

GUNDERSON, L. H. \& HOLLING, L., S.S (Eds.) (1995) Barriers and Bridges to the Renewal of Ecosystems and Institutions, New York, Columbia University Press.

GUNDERSON, L. H. \& HOLLING, L., S.S (Eds.) (2002) Panarchy; Understanding Transformations in Human and Natural Systems, Washington D.C, Island Press.

HODGSON, G. M. (1995) Economics and biology, Aldershot, Hants, England ; Brookfield, VT, E. Elgar Pub.

HOLDEN, J. (2005) Peatland hydrology and carbon cycling: why small-scale process matters. Philosophical Transactions of the Royal Society A, 363, 2891-2913.

HOLDEN, J., CHAPMAN, P. J., EVANS, M. G., HAYCOCK, N., HUBACEK, K., KAY, P. \& WARBURTON, J. (2007a) Vulnerability of organic soils in England and Wales. Defra Report SP0352, full technical report.

HOLDEN, J., SHOTBOLT, L., BONN, A., BURT, T. P., CHAPMAN, P. J., DOUGILL, A. J., FRASER, E. D. G., HUBACEK, K., IRVINE, B., KIRKBY, M. J., REED, M. S., PRELL, C., STAGL, S., STRINGER, L. C., TURNER, A. \& WORRALL, F. (2007b) Environmental change in moorland landscapes. Earth Science Reviews, 82, 75-100.

HOLliNG, C. S. (Ed.) (1978) Adaptive Environmental Assessment and Management, New York, John Wiley \& Sons.

HUBACEK, K., CHRISTINA PRELL, MARK REED, ALETTA BONN, DAN BOYS (2006) Using Stakeholder and Social Network Analysis to support participatory processes. International Journal of Biodiversity Science and Management 2, 249-252.

JANSSEN, M. A. (2002) Introduction. IN M.A, J. (Ed.) Complexity and Ecosystem Management: the theory and practice of multi-agent systems. Cheltenham, Edward Elgar Publishing Ltd.

JIN, N., TERMANSEN, M., HUBACEK, K., HOLDEN, J. \& KIRKBY, M. (2007) Adaptive Farming Strategies for Dynamic 
Economic Environments. Proceedings of the 2007 Congress on Evolutionary Computation (IEEE CEC). IEEE press.

KOLB, D. A. (1984) Experiential Learning: Experience as the source of learning and development, New Jersey, Prentice Hall.

MAGNUSZEWSKI, P., SENDZIMIR, J. \& KRONENBERG, J. (2005) Conceptual Modeling for Adaptive Environmental Assessment and Management in the Barycz Valley, Lower Silesia, Poland. International Journal of Environmental Research and Public Health, 2, 194-203.

MANSON, S. (2005) Agent-based modelling and genetic programming for modelling land change in the Southern Yucatan Peninsular Region of Mexico. Agriculture ecosystems \& environment, 111, 4762.

MARK, N. P. (2003) Culture and Competition: Homophily and Distancing Explanations for Cultural Niches. American sociological review, 68, 319-345.

MATTHEWS, R. (2006) The People and Landscape Model (PALM): Towards full integration of human decision-making and biophysical simulation models. Ecological Modelling, 194 329-343.

MILNE, R. \& BROWN, T. (1997) Carbon in the vegetation and soils of Great Britain. Journal of Environmental Management, 49, 413-433.

MITCHELL, R. K., AGLE, B. R. \& WOOD, D. J. (1997) Toward a theory of stakeholder identification and salience: Defining the principle of who and what really counts. Academy of Management Review, 22, 853-886.

MUSHOVE, P. \& VOGEL, C. (2005) Heads or tails? Stakeholder analysis as a tool for conservation area management. Global Environmental Change, 15, 184-198.

NEWMAN, L. \& DALE, A. (2007) Homophily and agency: creating effective sustainable development networks. Environment, development, and sustainability, 9, 79-90.

PAHL-WOSTL, C. (2002) Participative and Stakeholder-Based Policy Design, Evaluation and Modeling Processes. Integrated Assessment 3, 3-14.

PAHL-WOSTL, C. (2007) Transitions towards adaptive management of water facing climate and global change. Water Resources Management 21, 49-62.

PARKER, D. C., MANSON, S. M., JANSSEN, M. A., HOFFMANN, M. J. \& DEADMAN, P. J. (2003) Multi-agent systems for the simulation of land use and land cover change: a review. Ann. Assoc. Am. Geographers, 93, 316-340.

PEDERSEN, E. \& PERSSON WAYE, K. (2004) Perception and annoyance due to wind turbine noise-a dose-response relationship. Acoustical Society of America., 116, 3460-3470.

PRELL, C. (2003) Community networking and social capital: early investigations. . Journal of computermediated-communication, 8, http://jcmc.indiana.edu/vol8/issue3/prell.html

PRELL, C., HUBACEK, K., QUINN, C. \& REED, M. (2007a) 'Who's in the network?' When stakeholders influence data analysis. Systemic Practice And Action Research (SPAR). , Under Review.

PRELL, C., HUBACEK, K. \& REED, M. (2007b) Stakeholder analysis and social network analysis in natural resource management Society and Natural Resources, Under Review.

PRETTY, J. N., GUIJT, I., SCOONES, I. \& THOMPSON, J. (1995) A trainer's guide for participatory learning and action, London, UK, IIED.

RENN, O., WEBLER, T. \& WIEDEMANN, P. M. (1995) Fairness and competence in citizen participation: evaluating models for environmental discourse, Dordrecht; Boston, Kluwer Academic.

RUEF, M., ALDRICH, H. E. \& CARTER, N. M. (2004a) The Structure of Founding Teams: Homophily, Strong Ties, and Isolation among U.S. Entrepreneurs American Sociological Review, 69, 317317.

RUEF, M., ALDRICH, H. E. \& CARTER, N. M. (2004b) The Structure of Founding Teams: Homophily, Strong Ties, and Isolation among U.S. Entrepreneurs American Sociological Review

69, 317-317. 
SENDZIMIR, J., MAGNUSZEWSKI, P., BALOGH, P. \& VARI, A. (2007) Anticipatory modeling of biocomplexity in the Tisza river basin: First steps to establish a participatory adaptive framework. Environmental Modeling and Software, 22, 599-609

SHARMA, T., CARMICHAEL, J. \& KLINKENBERG, B. (2006) Integrated modeling for exploring sustainable agriculture futures. Futures 38, 93-113.

SIMON, H. (1955) A behavioral model of rational choice. Quarterly Journal of Economics, 69, 99-118.

SKVORETZ, J., FARARO, T. J. \& AGNEESSENS, F. (2004) Advances in biased net theory: definitions, derivations, and estimations. Social Networks, 26, 113-139.

SLOCUM, R., WICHART, L., ROCHELEAU, D. \& THOMAS-SLAYTER, B. (Eds.) (1995) Power, process and participation: tools for change, Exter, UK, Intermediate Technology Publications.

SMITH, G. (2003) Deliberative Democracy and the Environment, London and New York, Routledge.

STERMAN, J. (2000) Business Dynamics: Systems Thinking and Modeling for a Complex World, Irwin McGraw Hill.

STERMAN, J. (2002) All models are wrong. System Dynamics Review, 18, 501-531.

STRINGER, L. \& REED, M. (2006) Land degradation assessment in southern Africa: integrating local and scientific knowledge bases. Land Degradation \& Development, 18, 99-116.

TALLIS, J. H., MEADE, R. \& HULME, P. D. (1998) Introduction. IN TALLIS, J. H., MEADE, R. \& HULME, P. D. (Eds.) Blanket mire degradation. Proceedings. Manchester, British Ecological Society.

TRESS, B. \& TRESS, G. (2003) Scenario visualisation for participatory landscape planning - a study from Denmark. LANDSCAPE AND URBAN PLANNING, 64 161-178.

VAN DAALEN, E. C. \& BOTS, P. W. (2007) Participatory model construction and model use in natural resource management. Systemic Practice And Action Research, under review.

VAN DE KERKHOF, M. (2001) A survey on the methodology of participatory integrated assessment. Working paper IR-01-014. Laxenburg, Austria, International Institute for Applied Systems Analysis (IIASA)

VAN DEN BELT, M. (2004) Mediated Modeling: a systems dynamics approach to environmental consensus building, Washington, Covelo, London, Island Press.

VAN DER HEIJDEN, K. (1996) Scenarios: the art of strategic conversation, New York, John Wiley.

WALKER, B., S. , CARPENTER, J., ANDERIES, N., ABEL, G., CUMMING, M., JANSSEN, L., LEBEL, J., NORBERG, G. D., PETERSON \& R, P. (2002) Resilience management in socialecological systems: a working hypothesis for a participatory approach. Conservation Ecology, 6.

WALTERS, C. (1986) Adaptive management of renewable resources, New York, MacMillan.

WORRALL, F. \& BURT, T. (2005) Predicting the future DOC flux from upland peat catchments. Journal of Hydrology, 300, 126-139.

WORRALL, F., REED, M. S., WARBURTON, J. \& BURT, T. (2003) Carbon budget for a British peat catchment. Science of the Total Environment, 312, 133-146. 